\title{
Consumption of a Mango Fruit Powder Protects Mice from High-Fat Induced Insulin Resistance and Hepatic Fat Accumulation
}

\author{
Agustín G. Sabater ${ }^{\mathrm{a}}$ Joan Ribot ${ }^{\mathrm{a}} \quad$ Teresa Priego $^{\mathrm{a}, \mathrm{d}} \quad$ Itxaso Vazquez $^{\mathrm{c}}$ Sonja Frank ${ }^{\mathrm{b}}$ \\ Andreu Palou ${ }^{a}$ Sybille Buchwald-Werner ${ }^{c}$ \\ aNutrigenomic and Obesity research group, Laboratory of Molecular Biology, Nutrition and \\ Biotechnology, Universitat de les Illes Balears and CIBER Fisiopatología de la Obesidad y Nutrición \\ (CIBERobn), Palma de Mallorca, Spain; bVital Solutions Swiss AG, Romanshorn, Switzerland; ' Vital \\ Solutions GmbH, Langenfeld, Germany; ${ }^{\mathrm{d} D e p a r t m e n t}$ of Physiology, Universidad Complutense, Madrid, \\ Spain
}

\section{Key Words}

Mangifera indica $•$ Metabolic syndrome $\cdot$ Insulin sensitivity $•$ Hepatic steatosis $•$ Healthy body composition • Weight management $\bullet$ Food ingredient $\bullet$ Metabolism

\begin{abstract}
Background/Aims: The aim of this study was to gain more insight into the beneficial effects of mango fruit powder on the early metabolic adverse effects of a high-fat diet. Methods: The progressive dose-response effects of mango fruit powder on body composition, circulating parameters, and the expression of genes related to fatty acid oxidation and insulin sensitivity in key tissues were studied in mice fed a moderate (45\%) high-fat diet. Results: Findings suggest that mango fruit powder exerts physiological protective effects in the initial steps of insulin resistance and hepatic lipid accumulation induced by a high-fat diet in mice. Moreover, AMPK and SIRT1 appear as key regulators of the observed improvement in fatty acid oxidation capacity, as well as of the improved insulin sensitivity and the increased glucose uptake and metabolism through the glycolytic pathway capacity in liver and skeletal muscle. Conclusion: In summary, this study provides evidence that the functional food ingredient (Careless ${ }^{\mathrm{TM}}$ ) from mango fruit prevents early metabolic alterations caused by a high-fat diet in the initial stages of the metabolic syndrome.

\section{Introduction}

Dysregulated glucose and lipid metabolism and, thus, energy homeostasis are early events in the development of insulin resistance, which in turn may lead to obesity and diabetes mellitus type 2 . The overall prevalence of insulin resistance in developed societies A. Palou and S. Buchwald-Werner contributed equally to this work. 


\section{Cellular Physiology Cell Physiol Biochem 2017;42:564-578

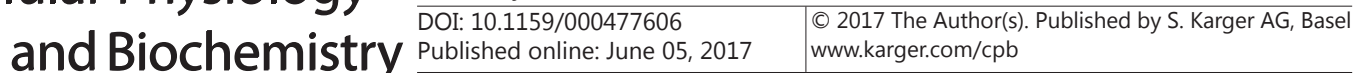 \\ Sabater et al.: Mango Fruit on Early Metabolic Adverse Effects of a High-Fat Diet}

is high, with $11.5-14.0 \%$ of the European population [1], 20\% of adults in Japan [2], and nearly $30 \%$ of adult Americans [3] being afflicted. The insensitivity of peripheral tissues to the effects of insulin starts when the nutrient storage metabolic pathways are exposed to persistent energy excess, surpassing the capacity of the catabolic pathways. Significant insulin resistance has been described in rats after just three weeks on a high-fat diet [4]. In particular, dietary saturated fat has long been considered a driver of insulin resistance. Thus, ectopic lipid accumulation in liver and skeletal muscle triggers pathways which may impair insulin signaling, leading to reduced muscle glucose uptake [5]. Non-alcoholic fatty liver disease (NAFLD), associated with insulin resistance, obesity, type 2 diabetes, metabolic syndrome and high fat consumption, is also growing and is rapidly becoming the most common liver disease worldwide [6-9].

Mango (Mangifera indica Linn.) is a globally consumed fruit with reported healthpromoting properties [10-13] and, based on studies in rats [14, 15] and humans [16, 17], its habitual consumption may contribute to the prevention of diabetes mellitus, obesity, and related complications. In addition, it has been reported that the food ingredient Careless ${ }^{\mathrm{TM}}$, a $100 \%$ pure mango fruit powder characterized by a high content in secondary plant metabolites, including gallic acid, rutin and mangiferin (MGF) [18], activates sirtuin 1 (SIRT1) and AMP-activated protein kinase (AMPK) in cell systems [19], which are both involved in energy homeostasis and glucose and lipid metabolism. Moreover, a recent intervention study in humans reported moderate beneficial effects of the same mango fruit powder on microcirculation and endothelial function [18], mediated, at least partly, by the activation of endothelial nitric oxide synthase [18]. Similar results from studies with rats [15] and human umbilical vein cells [20] also suggest that polyphenols of aqueous extracts of Mango may protect endothelial cells. These results are of interest considering that impaired microvascular function is observed early in the development of type 2 diabetes mellitus and cardiovascular disease [21].

Here we aimed to test the potential applicability of the functional food ingredient Careless ${ }^{\mathrm{TM}}$ in the prevention of the metabolic alterations caused by a high-fat diet in the early stages of the metabolic syndrome (which we have recently reviewed [22]) by feeding mice a moderate (45\%) high-fat diet for 10 weeks, considered an appropriate experimental model to test the potential protective qualities of functional ingredients. For this, we determined its effects on body composition, insulin resistance, and the expression of genes related to fatty acid oxidation and insulin sensitivity in key metabolic tissues.

\section{Materials and Methods}

Mango fruit powder

Careless $^{\mathrm{TM}}$ (Vital Solutions Swiss AG; Romanshorn, Switzerland), currently used in dietary supplements and functional foods, is a $100 \%$ pure fruit powder obtained from the Mangifera indica variety Kili mooku, cultivated in the Tamil Nadu region of India. The fruits of mango are still green and hard when harvested; they are then sliced, dried, and subsequently ground to the final product. Compared to ripe mango fruits, this degree of ripeness is characterized by a higher content of secondary plant ingredients and a lower sugar content. The typical nutritional composition and the range of concentrations of MGF of the food ingredient Careless $^{\mathrm{TM}}$ are shown in Table 1. Other natural phenolic compounds, such as gallic acid or rutin, have been also identified [18].

\section{Experimental animals, diets, and study design}

The experiment was performed in accordance with the national and European ethical guidelines for the use and care of laboratory animals. The Bioethical Committee of the University of the Balearic Islands approved the experimental protocol. 4-week-old C57BL/6J male mice (CRL España, Barcelona, Spain) were housed 3-4 per cage at $21^{\circ} \mathrm{C}$, with a 12 -h light/dark cycle (lights on at 08:00 a.m.) and free access to food and water. Mice were divided into five experimental groups (10-12 animals/group): four groups were fed a defined high-fat diet with 45\% energy as fat (D12451 from Research Diets Inc., New Brunswick, NJ, USA) and treated with water (vehicle) (high-fat control group, HFC) or with Careless ${ }^{\text {tw }}$ (Vital Solutions Swiss AG, 


\section{Cellular Physiology Cell Physiol Biochem 2017;42:564-578

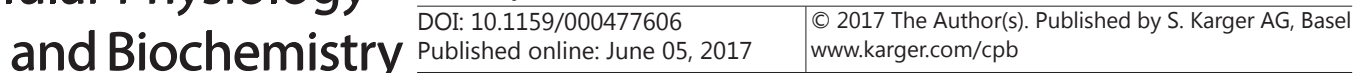

Sabater et al.: Mango Fruit on Early Metabolic Adverse Effects of a High-Fat Diet

Romanshorn, Swiss; referred from hereafter as mango fruit powder) at three different doses $(18,54$, and 108 $\mathrm{mg} / \mathrm{kg}$ bw/day; T1, T2, and T3 groups, respectively), and an additional group was fed with a standard chow diet with 8\% energy from fat (A04 from Panlab, S.L.U., Barcelona, Spain; normal fat control group, NFC) and treated with water (vehicle) as a reference group. The administered doses of mango fruit powder for mice were estimated by applying an equivalent daily dose [23] from dosages previously used in a human doubleblind study [18]. The duration of the experiment was ten weeks and treatments were conducted daily by oral administration, with the aid of a pipette $(20 \mu \mathrm{L})$, between 9.00 a.m. and 12.00 a.m. Body weight, body composition, and food intake were regularly monitored. Food intake was estimated on a per-cage basis (3-4
Table 1. Typical nutritional composition and the range of Mangiferin concentrations in the mango fruit powder Careless ${ }^{\mathrm{TM}}$. Data from Vital Solutions Swiss AG (Romanshorn, Switzerland)

\begin{tabular}{lc}
\hline & Per $100 \mathrm{~g}$ \\
\hline Energy: & $299 \mathrm{kcal}$ \\
Carbohydrates: & $61.2 \mathrm{~g}$ \\
Sugar: & $24.5 \mathrm{~g}$ \\
Fat: & $0.3 \mathrm{~g}$ \\
trans-Fat: & $<0.1 \mathrm{~g}$ \\
Cholesterol: & Not detected \\
Protein: & $2.7 \mathrm{~g}$ \\
Total Dietary fiber (incl. inulin): & $25.89 \mathrm{~g}$ \\
Soluble fiber (incl. inulin reduction): & $16.73 \mathrm{~g}$ \\
Insoluble fiber (incl. inulin reduction): & $9.10 \mathrm{~g}$ \\
Ash: & $2.42 \mathrm{~g}$ \\
Sodium: & $11.8 \mathrm{mg}$ \\
Mangiferin: & $30-70 \mathrm{mg}$ \\
\hline
\end{tabular}

animals/cage) from the actual amount of food consumed by the animals and its caloric equivalence. Body composition was analyzed using an EchoMRI-700 ${ }^{\mathrm{TM}}$ analyzer (LCC, Houston, TX, USA). Animals were killed by decapitation within the first $2 \mathrm{~h}$ of the light cycle. Liver, skeletal muscle (gastrocnemius) and adipose tissue depots were dissected in their entirety, weighed, snap-frozen in liquid nitrogen, and stored at $-80^{\circ} \mathrm{C}$ until analysis. Serum was obtained from blood collected from the neck and stored at $-80^{\circ} \mathrm{C}$ until analysis. Elongated pieces of livers were fixed for morphological analysis (see below).

\section{Measurement of blood parameters and determination of HOMA-IR}

Blood glucose concentration was measured using an automatic device (Accu-Chek Aviva system; Roche Diagnostics, Barcelona, Spain); plasma and serum insulin (Mercodia AB, Uppsala, Sweden), serum adiponectin and serum leptin (R\&D Systems, Minneapolis, MN, USA) concentrations were measured using commercial ELISA kits; and serum free fatty acids (FFA; Wako Chemicals GmbH, Neuss, Germany), total cholesterol, low-density lipoprotein (LDL)-cholesterol and high-density lipoprotein (HDL)-cholesterol (QCA, Tarragona, Spain), and triglycerides (TG; Triglyceride (INT) 20 from Sigma Diagnostics, St. Louis, MO, USA) were measured using colorimetric and enzymatic standard methods according to the manufacturers' instructions.

Insulin resistance was assessed using the homeostatic model assessment for insulin resistance (HOMA-IR) score derived from circulating concentrations of insulin and glucose in animals after a 6-h fast (from 6.00 a.m. to 12.00 a.m.), and calculated as described [24].

\section{Hepatic triglyceride quantification}

A sample of liver (100-200 mg) was homogenized in PBS (137 mM NaCl, $2.7 \mathrm{mM} \mathrm{KCl}$ and $10 \mathrm{mM}$ phosphate buffer, $\mathrm{pH}$ 7.4). Tissue homogenates were centrifuged at $500 \mathrm{x} g$ for $10 \mathrm{~min}$ and the supernatant was used for quantification. Total triglyceride concentrations were measured using a commercial colorimetric and enzymatic kit following standard procedures (Triglyceride (INT) 20 from Sigma Diagnostics, St. Louis, MO, USA).

\section{Histological Studies}

Pieces of dissected liver were fixed by immersion in 4\% paraformaldehyde in $0.1 \mathrm{M}$ phosphate buffer (pH 7.4) overnight at $4{ }^{\circ} \mathrm{C}$. To assess liver histology, fixed pieces were washed in phosphate buffer, dehydrated in a graded series of ethanol, cleared in xylene, embedded in paraffin blocks, cut into $5 \mu \mathrm{m}$ sections and stained with hematoxylin and eosin (H\&E). For the histological visualization of neutral fat, fixed pieces were washed in phosphate buffer and embedded in $30 \%$ sucrose, stored at $-80^{\circ} \mathrm{C}$, cut into $15 \mu \mathrm{m}$ sections with a cryostat, and stained with Oil Red O Stain Kit (Abcam, Cambridge, UK) according to the manufacturer's instructions.

A Zeiss Axioskop 2 microscope equipped with an AxioCam ICc3 digital camera and AxioVision 40V 4.6.3.0 software (Carl Zeiss, Barcelona, Spain) was used. 


\section{Cellular Physiology Cell Physiol Biochem 2017;42:564-578 \begin{tabular}{c|c|c|} 
DOI: 10.1159/000477606 & O 2017 The Author(s). Published by S. Karger AG, Basel \\
www.karger.com/cpb
\end{tabular}}

Sabater et al.: Mango Fruit on Early Metabolic Adverse Effects of a High-Fat Diet

Gene expression analysis

Total RNA was extracted from the different tissues using Tripure Isolation Reagent (Sigma-Aldrich, Spain) according to the supplier's instructions. RNA was further purified by standard ethanol/sodium acetate precipitation. The concentration and purity of RNA was estimated using a Nano-Drop 1000 instrument (Thermo-Fisher Scientific, Waltham, MA, USA). RNA was analysed for integrity on a $1 \%$ agarose gel stained with SYBRSafe (Life Technologies, Carlsbad, CA, USA) and stored at $-80^{\circ} \mathrm{C}$ until analysis.

Total RNA (200 ng per reaction) was retrotranscribed using a MuLV Reverse Transcriptase-based dedicated kit (Life Technologies, Grand Island, NY, USA), using random hexamers priming. mRNA expression of the genes of interest was analysed by real-time PCR using the StepOnePlus system with SYBR Green I sequence-nonspecific detection (Life Technologies) as described before [25] and following the MIQE guidelines [26]. For each reaction, Power SYBR Green Master mix (Life Technologies), $250 \mathrm{nM}$ of forward and reverse primers, and $2 \mathrm{ng}$ cDNA-equivalents were used. Following amplification, a melt curve analysis was performed in each plate. The sequences of the primer sets used are available upon request. Raw amplification data (Rn) were exported and used to determine the cycle of quantification using the LinRegPCR software [27]. Relative gene expression was calculated using the $2^{-\Delta \Delta c t}$ method [28]. Gene expression data were normalized against a reference gene, which we identified as a good constitutive gene from at least two potential ones for all the samples in the respective tissues.

\section{Western blot analysis}

Total protein was extracted from gastrocnemius muscle by homogenization in RIPA buffer containing Halt Protease and Phosphatase Inhibitor Cocktail (Thermo Fisher, Rockford, IL, USA). BCA method (Thermo Fisher) was used to measure total protein amount. Protein (50 $\mu \mathrm{g}$ ) was loaded and separated in a precast 4-15\% gradient gel (Bio-Rad, Hercules, CA, USA), and transferred onto a $0.45 \mu \mathrm{m}$ nitrocellulose membrane using a Trans-Blot Turbo semi-dry transfer apparatus (Bio-Rad). Membranes were blocked for $1 \mathrm{~h}$ at room temperature with Odyssey Blocking Buffer (Li-Cor, Lincoln, NE, USA) and incubated overnight at $4^{\circ} \mathrm{C}$ with gentle shaking with primary antibodies (1:1000 in Tris Buffered Saline-Tween 20, TBS-T). The following were used: anti-AKT (\#9272), anti-phosphoSer473-AKT (\#4051), anti-AMPKa (\#2793), anti-phosphoThr172AMPK $\alpha$ (\#2535) and anti-HSP90 (\#4877) antibodies from Cell Signaling (Danvers, MA, USA). Membranes were then incubated with the corresponding secondary IRDye antibodies (1:20000 in TBS-T, $1 \mathrm{~h}$ at room temperature). The signal was detected by an Odyssey near-infrared scanner (Li-Cor) and the bands were quantified using the Odyssey V3.0 (Li-Cor) software.

\section{Statistical analysis}

Data are presented as mean \pm standard error of the mean (SEM). The extreme studentized deviate (ESD) method was used to determine whether one of the values was a significant outlier from the rest using the GraphPad web tool (http://graphpad.com/quickcalcs/Grubbs1.cfm). The one-way ANOVA model followed by post hoc analysis using Fisher's least square means (LSD) separation test when F values were significant was applied to analyse the statistical significance of treatment effects. Single comparisons with control group were assessed by Student's $t$ test. Differences were considered significant at $\mathrm{P}<0.05$. The analyses were performed using the SPSS program for Windows version 20 (SPSS, Chicago, IL).

\section{Results}

Effects of mango fruit powder on biometric parameters

High-fat diet-fed control animals (HFC) had significantly higher body weight, body fat, and adipose tissue weights, and their subcutaneous/visceral adipose tissue ratio was lower compared to animals fed the normal fat control diet (NFC) (Table 2). Mango fruit powder treatment did not significantly change this; however, animals in the group treated with 54 $\mathrm{mg} / \mathrm{kg}$ bw/day (T2) had an intermediate body weight that did not significantly differ from both the HFC and the NFC group.

Furthermore, among the animals fed the high-fat diets, those from group T2 had the lowest body fat and adipose tissue depot weights after 10 weeks, whereas the group treated 
with the highest dose (T3) had the highest body fat and adipose tissue depot weights. Animals from T2 were also the ones with the highest subcutaneous/visceral adipose tissue ratio among all groups fed a HF diet. No major differences were observed among groups regarding lean body mass and weight of brown adipose tissue (BAT), liver and gastrocnemius muscle (Table 2).

\section{Effects of mango fruit powder on blood parameters}

Blood glucose and lipids. Non-fasted HFC animals had higher concentrations of glucose, free fatty acids, and cholesterol (total, LDL and HDL) compared to animals fed the NFC diet (Table 3). Mango fruit powder-treated groups showed a similar metabolic profile to the vehicle treated HFC group. However, animals receiving $54 \mathrm{mg} / \mathrm{kg}$ bw/day (T2) tended to have lower LDL cholesterol concentrations compared to all animals fed the HF diet (HFC,

Table 2. Effect of mango fruit powder suplementation treatment on biometric parameters in high-fat dietfed animals. Obesity-prone mice were fed for 10 weeks a high-fat diet (HFC group) or a high-fat diet with simultaneous oral daily treatment with 18,54 , or $108 \mathrm{mg} / \mathrm{kg}$ bw/day of mango fruit powder (T1, T2, and T3 group, respectively), whereas control animals were fed a normal fat standard chow diet (NFC group). Data are the means \pm SEM $(n=10-12)$. Statistically significant differences between treatments in high-fat diet-fed animals were tested by one-way ANOVA and least-significant difference (LSD) post hoc comparisons (P < 0.05 ) and values not sharing a common letter were statistically different. Statistically significant differences versus NFC group were assessed by a two-tailed Student's t test $(\mathrm{P}<0.05)$ and indicated by an asterisk. WAT: white adipose tissue, BAT: brown adipose tissue. ${ }^{1}$ Body composition was analyzed using EchoMRI-700 ${ }^{\text {TM }}$ analyzer (LCC, Houston, TX, USA). ${ }^{2}$ Defined as the ratio between the sum of the mass of subcutaneous depots of adipose tissue (i.e. inguinal) and the sum of the mass of visceral depots of adipose tissue (i.e. epididymal and retroperitoneal)

\begin{tabular}{|c|c|c|c|c|c|c|c|c|c|c|c|}
\hline \multirow[b]{2}{*}{ Body weight (g) } & \multicolumn{3}{|c|}{ NFC } & \multicolumn{2}{|r|}{$\mathrm{HFC}$} & \multicolumn{2}{|r|}{ T1 } & \multicolumn{2}{|r|}{$\mathrm{T} 2$} & \multicolumn{2}{|r|}{ T3 } \\
\hline & 27.8 & \pm & 0.3 & 31.1 & $\pm 0.7^{*}$ & 31.4 & $\pm 0.9^{*}$ & 29.2 & \pm 0.7 & 31.9 & $\pm 0.4^{*}$ \\
\hline Lean body mass $(\mathrm{g})^{1}$ & 24.1 & \pm & 0.36 & 24.5 & \pm 0.60 & 24.2 & \pm 0.31 & 23.8 & \pm 0.45 & 24.1 & \pm 0.35 \\
\hline Body fat $(\mathrm{g})^{1}$ & 1.90 & \pm & 0.14 & 4.21 & $\pm 0.56^{\mathrm{ab} *}$ & 4.62 & $\pm 0.74 \mathrm{ab} *$ & 3.33 & $\pm 0.33 a^{*}$ & 5.49 & $\pm 0.41 \mathrm{~b} *$ \\
\hline Inguinal WAT weight (mg) & 259 & \pm & 12 & 478 & $\pm 49 *$ & 501 & $\pm 78^{*}$ & 417 & $\pm 32^{*}$ & 600 & $\pm 36^{*}$ \\
\hline Epididymal WAT weight (mg) & 361 & \pm & 23 & 964 & $\pm 129 a b *$ & 919 & $\pm 160 \mathrm{ab} *$ & 677 & \pm 61 a* & 1,181 & $\pm 72 \mathrm{~b} *$ \\
\hline Retroperitoneal WAT weight (mg) & 75 & \pm & 7 & 285 & $\pm 48 \mathrm{ab} *$ & 318 & $\pm 61 \mathrm{ab} *$ & 195 & $\pm 20^{*} *$ & 371 & $\pm 33 \mathrm{~b} *$ \\
\hline Adipose tissue subcutaneous/visceral ratio 2 & 0.61 & \pm & 0.03 & 0.41 & $\pm 0.04 \mathrm{a}^{*}$ & 0.41 & $\pm 0.03 \mathrm{a}^{*}$ & 0.47 & $\pm 0.01 \mathrm{~b} *$ & 0.39 & $\pm 0.01 \mathrm{a}^{*}$ \\
\hline Interscapular BAT weight (mg) & 88 & \pm & 6 & 97 & \pm 7 & 113 & \pm 12 & 95 & \pm 6 & 116 & $\pm 4^{*}$ \\
\hline Liver weight (g) & 1.28 & \pm & 0.05 & 1.27 & \pm 0.06 & 1.32 & \pm 0.05 & 1.30 & \pm 0.03 & 1.30 & \pm 0.06 \\
\hline Gastrocnemius muscle weight (mg) & 318 & \pm & 7 & 326 & \pm 13 & 328 & \pm 6 & 331 & & 316 & \pm 10 \\
\hline
\end{tabular}

Table 3. Effect of mango fruit powder supplementation on circulating serum parameters and blood glucose under the fed state in high-fat diet-fed animals. Obesity-prone mice were fed for 10 weeks a high-fat diet (HFC group) or a high-fat diet with simultaneous oral daily treatment with 18, 54, or $108 \mathrm{mg} / \mathrm{kg}$ bw/day of mango fruit powder (T1, T2, and T3 group, respectively), whereas control animals were fed a normal fat standard chow diet (NFC group). Data are the means \pm SEM $(n=10-12)$. Statistically significant differences between treatments in high-fat diet-fed animals were tested by one-way ANOVA and least-significant difference (LSD) post hoc comparisons $(\mathrm{P}<0.05)$ and values not sharing a common letter were statistically different. Statistically significant differences versus NFC group were assessed by a two-tailed Student's t test $(\mathrm{P}<0.05)$ and indicated by an asterisk

\begin{tabular}{|c|c|c|c|c|c|c|c|c|c|c|c|c|c|c|c|}
\hline & \multicolumn{3}{|c|}{ NFC } & \multicolumn{3}{|c|}{ HFC } & \multicolumn{3}{|c|}{ T1 } & \multicolumn{3}{|c|}{$\mathrm{T} 2$} & \multicolumn{3}{|c|}{ T3 } \\
\hline Glucose $(\mathrm{mM})$ & 7.54 & \pm & 0.18 & 8.16 & \pm & 0.40 & 8.33 & \pm & $0.30^{*}$ & 7.58 & \pm & 0.38 & 8.43 & \pm & $0.41^{*}$ \\
\hline Triglycerides $(\mathrm{mg} / \mathrm{mL})$ & 1.04 & \pm & 0.09 & 1.04 & \pm & 0.12 & 1.18 & \pm & 0.10 & 1.28 & \pm & 0.09 & 1.22 & \pm & 0.11 \\
\hline Free fatty acids (mM) & 1.24 & \pm & 0.10 & 1.46 & \pm & 0.10 & 1.61 & \pm & $0.12^{*}$ & 1.68 & \pm & $0.15^{*}$ & 1.62 & \pm & 0.18 \\
\hline Total cholesterol (mg/dL) & 164 & \pm & 7 & 253 & \pm & $17^{*}$ & 275 & \pm & $6^{*}$ & 267 & \pm & $9^{*}$ & 259 & \pm & $13^{*}$ \\
\hline HDL cholesterol (mg/dL) & 98 & \pm & 6 & 150 & \pm & $11^{*}$ & 166 & \pm & $7^{*}$ & 158 & \pm & $7^{*}$ & 161 & \pm & $11^{*}$ \\
\hline LDL cholesterol (mg/dL) & 54.8 & \pm & 3.5 & 80.7 & \pm & $9.7 *$ & 89.2 & \pm & $4.6^{*}$ & 70.4 & \pm & 7 & 85.4 & \pm & $8.5^{*}$ \\
\hline Total C/HDL-C ratio & 1.69 & \pm & 0.05 & 1.71 & \pm & 0.05 & 1.67 & \pm & 0.04 & 1.70 & \pm & 0.05 & 1.64 & \pm & 0.05 \\
\hline LDL-C/HDL-C ratio & 0.56 & \pm & 0.03 & 0.52 & \pm & 0.04 & 0.54 & \pm & 0.02 & 0.44 & \pm & $0.04 *$ & 0.54 & \pm & 0.04 \\
\hline Leptin $(\mathrm{ng} / \mathrm{mL})$ & 3.9 & \pm & 0.6 & 19.6 & \pm & $5.9 \mathrm{ab} *$ & 18.6 & \pm & $4.6 \mathrm{ab} *$ & 11.1 & \pm & $1.5 \mathrm{a}^{*}$ & 25.0 & \pm & $3.8 \mathrm{~b} *$ \\
\hline in $(\mu \mathrm{g} / 1$ & 11.9 & \pm & 0.6 & 10.6 & \pm & 1.0 & 11.0 & \pm & 0.8 & 9.96 & \pm & $0.4^{*}$ & 11.9 & \pm & 1.0 \\
\hline Leptin/adiponectin ratio & 0.32 & \pm & 0.06 & 1.81 & \pm & $0.51^{*}$ & 1.62 & \pm & $0.34^{*}$ & 1.21 & \pm & $0.09^{*}$ & 2.11 & \pm & $0.35^{*}$ \\
\hline $\mathrm{TNF} \alpha(\mathrm{pg} / \mathrm{mL})$ & 3.25 & \pm & 1.92 & 4.03 & \pm & 1.46 & 1.29 & \pm & 0.85 & 4.83 & \pm & 3.31 & 3.19 & \pm & 1.76 \\
\hline IL-6 (p & 134 & \pm & 43.2 & 98.4 & \pm & 32.1 & 84.0 & \pm & 26.6 & 120 & \pm & 22.4 & 115 & \pm & 21.5 \\
\hline AST $(I U / L)$ & 127.0 & \pm & 17.6 & 97.0 & \pm & 15.4 & 167 & \pm & 18.8 & 95.7 & \pm & 29.6 & 168 & \pm & 51.0 \\
\hline
\end{tabular}



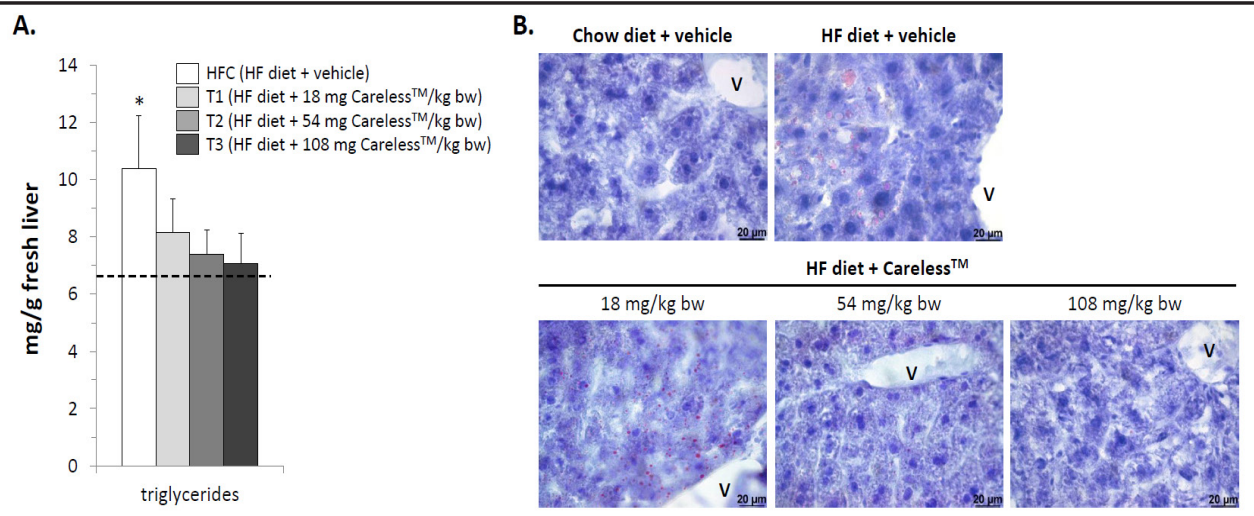

Fig. 1. Effect of mango fruit powder suplementation on triglcyeride content in liver of high-fat diet-fed animals. Obesity-prone mice were fed for 10 weeks with a high-fat diet (HFC group) or a high-fat diet with simultaneous oral daily treatment with 18,54 , or $108 \mathrm{mg} / \mathrm{kg}$ bw/day of mango fruit powder (T1, T2, and T3 group, respectively), whereas control animals were fed a normal fat standard chow diet (NFC group). (A) Data are the means \pm SEM ( $n=10-12)$. The horizontal dotted line represents the mean of NFC group. Statistically significant differences versus NFC group were assessed by a two-tailed Student's $t$ test $(P<0.05)$ and indicated by an asterisk. (B) Representative microphotographies of liver sections stained with Oil Red O Stain (see Materials and Methods section).

T1, T3) and a lower LDL-cholesterol/HDL-cholesterol ratio. TG concentrations and the total cholesterol/HDL-ratio were similar in all groups (Table 3).

Adipokines, inflammation, and liver damage markers in blood. Serum adipokine concentrations largely reflected adipose tissue mass. Leptin concentrations and the leptin/ adiponectin ratio were significantly higher in all high-fat diet-fed groups. Among these, animals in the T2 group had the lowest and those in T3 the highest leptin concentrations and leptin/adiponectin ratio, respectively (Table 3).

Concentrations of Tumor necrosis factor (TNF) $\alpha$ and Interleukin (IL)-6, as well as aspartate aminotransferase (AST) activity, were similar in all groups suggesting no signs of inflammation or tissue damage due to dietary intervention and treatment (Table 3).

Effects of mango fruit powder on liver parameters

Compared to NFC, all groups on the high-fat diet had lower relative liver weights (as a percentage of body weight) as a consequence of the increase in relative body fat (Table 2 ). Treatment with mango fruit powder did not affect relative liver weight. The TG content of the liver was significantly higher in animals fed the HFC diet compared to NFC animals. Treatment with mango fruit powder protected against this high-fat diet-induced increase in hepatic TG dose-dependently, as seen by the biochemical analysis and the direct oil-red staining of the liver (Fig. 1A and 1B, respectively). Moreover, H\&E histological analysis of the liver (data not shown) revealed evidence of Grade I NAFLD [29, 30] in 1/8 animals studied in the HFC group and in another (1/8 studied) among the animals treated with the low dose (T1 group), whereas none of the animals out of the NFC, T2 and T3 treated animals (8-11 studied per group) showed evidence of hepatic steatosis.

Effects of mango fruit powder treatment on insulin sensitivity in mice

In order to study the changes in insulin sensitivity of the animals over time, fasting glucose and insulin concentrations were determined and HOMA-IR scores calculated after 1 , 5 , and 9 weeks of dietary challenge and intervention.

After week 1, fasting glucose concentrations were significantly increased in animals fed the high-fat diets compared to NFC animals (Fig. 2A). After week 5, this increase was normalized to the fasting glucose concentrations of the NFC animals, whereas fasting insulin concentrations (Fig. 2C) and HOMA-IR scores (Fig. 2E) were increased. Mango fruit powder treatment, particularly at the medium dose (T2), normalized (or even reduced) fasting KARGER 
Fig. 2. Effect of mango fruit powder suplementation on fasting glucose blood (A and $\mathrm{B}$ ) and insulin plasma levels ( $\mathrm{C}$ and D), and the HOMA-IR score (E and F) in high-fat diet-fed animals at weeks 1, 5, and 9 of dietary challenge and intervention. Obesity-prone mice were fed for 10 weeks with a high-fat diet (HFC group) or a high-fat diet with simultaneous oral daily treatment with 18,54 , or $108 \mathrm{mg} /$ $\mathrm{kg}$ bw/day of mango fruit powder (T1, $\mathrm{T} 2$, and $\mathrm{T} 3$ group, respectively), whereas control animals were fed a normal fat standard chow diet (NFC group). Data are the means \pm SEM $(n=10-12)$. In $B, D$ and $\mathrm{F}$ data represent the change from week 1 to week 9 of dietary challenge and intervention. The horizontal dotted line represents the mean of NFC group. Statistically significant differences between treatments in high-fat diet-fed animals were tested by one-way ANOVA and least-significant difference (LSD) post hoc comparisons $(\mathrm{P}<0.05)$ and values not sharing a common letter were statistically different. Statistically significant differences versus NFC group were assessed by a two-tailed Student's t test $(\mathrm{P}<0.05)$ and indicated by an asterisk. Statistically differences versus week 1 were assessed by a two-tailed Student's t test $(\mathrm{P}<0.05)$ and indicated by a hash symbol.

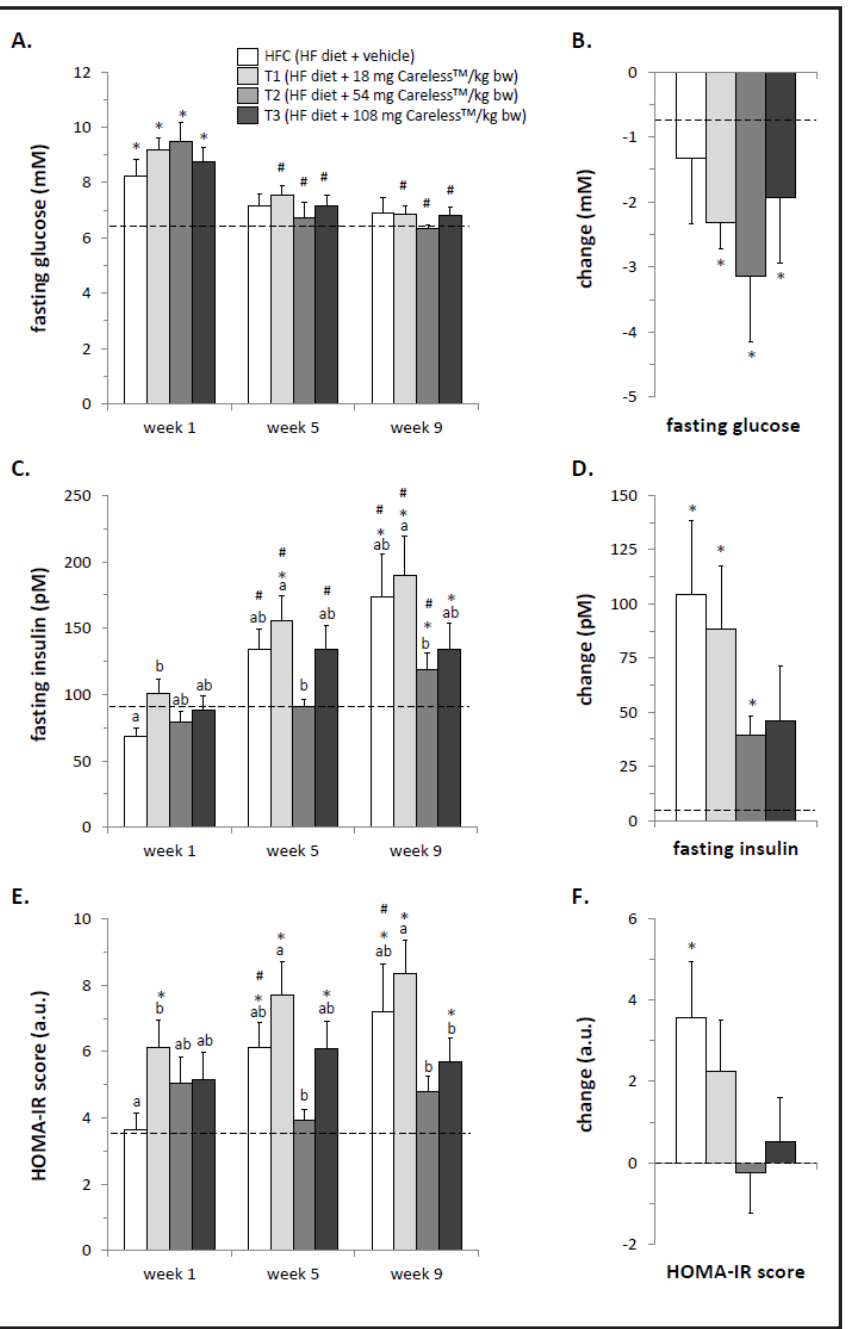

glucose levels to NFC levels (Fig. 2A and B) with lower fasting insulin levels (Fig. 2C and $2 \mathrm{D}$ ), providing protection against this high-fat diet-induced increase in insulin resistance as reflected in the statistically significant (two-tailed Student's t test; $\mathrm{P}<0.05$ ) reduction in the HOMA-IR score between T2 and HF control groups (Fig. 2E and 2F).

Effects of mango fruit powder on the expression of genes related to fatty acid oxidation and insulin signaling in the liver

Fig. 3 summarizes the statistically significant changes elicited by mango fruit powder treatment in the mRNA expression levels of the studied hepatic genes encoding transcription-related factors, metabolic enzymes, and signal proteins involved in glucose and lipid catabolism, as well as receptors and proteins involved in insulin signaling. Relative mRNA expression of peroxisome proliferator activated receptor alpha (Ppara) and carnitine palmitoyltransferase 1a (Cpt1a) tended to increase in the HFC group compared to NFC. Furthermore, Careless ${ }^{\mathrm{TM}}$ treatment significantly increased the expression of both genes compared to NFC mice, and at the highest dose (108 mg/kg bw/day), relative Cpt1a mRNA levels were significantly higher than in HFC animals. Compared to NFC mice, HFC animals had similar relative mRNA expression of peroxisome proliferator-activated receptor gamma (Pparg) in the liver. Intervention with Careless $^{\mathrm{TM}}$ significantly decreased hepatic Pparg expression compared to NFC and, at the lowest dose, compared to HFC (Fig. 3).

mRNA expression levels of the catalytic subunit alpha 1 of AMP-activated protein kinase (Prkaa1) were significantly decreased in animals fed the HFC compared to NFC mice. Mango 


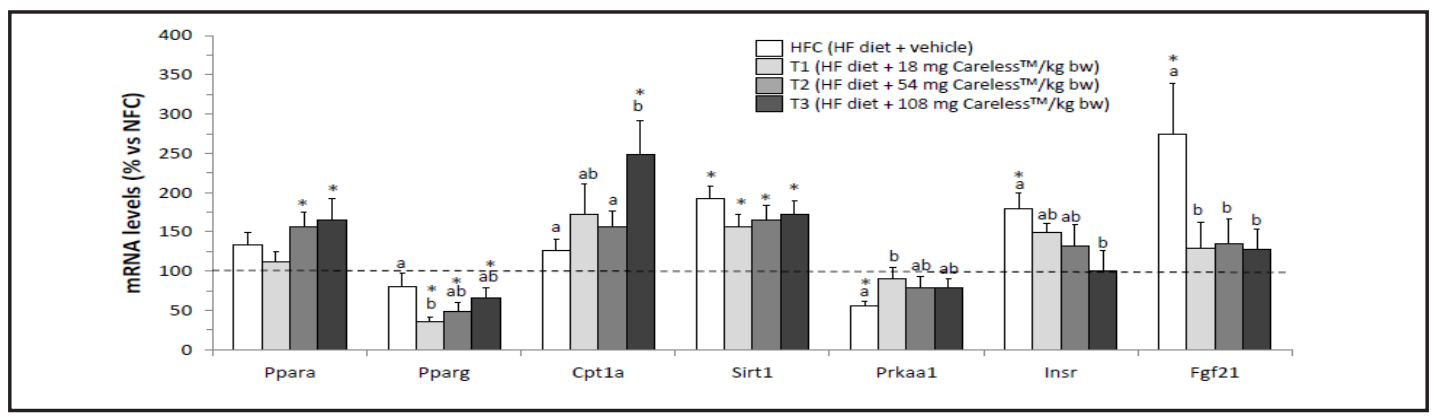

Fig. 3. Effect of mango fruit powder suplementation on transcriptional response in liver of high-fat diet-fed animals. Obesity-prone mice were fed for 10 weeks with a high-fat diet (HFC group) or a high-fat diet with simultaneous oral daily treatment with 18,54 , or $108 \mathrm{mg} / \mathrm{kg}$ bw/day of mango fruit powder (T1, T2, and T3 group, respectively), whereas control animals were fed a normal fat standard chow diet (NFC group). The specific mRNA levels were quantified by real-time RT-PCR and normalized to the expression of the reference gene Gdi. Data are the means \pm SEM $(n=9-12)$ and are expressed relative to the mean value of the NFC group, which was set to 100 . The horizontal dotted line represents the mean of the NFC group. Statistically significant differences between treatments in high-fat diet-fed animals were tested by one-way ANOVA and least-significant difference (LSD) post hoc comparisons $(\mathrm{P}<0.05)$ and values not sharing a common letter were statistically different. Statistically significant differences versus NFC group were assessed by a twotailed Student's t test $(\mathrm{P}<0.05)$ and indicated by an asterisk.

fruit powder treatment counteracted this decrease, especially at the lowest dose tested (Fig. 3). In addition, hepatic sirtuin 1 (Sirt1) mRNA expression was significantly higher in all animals fed a high-fat diet than in control animals. Mango fruit powder treatment did not affect Sirt1 expression in the liver (Fig. 3).

HFC diet intake increased relative mRNA levels of insulin receptor (Insr) and fibroblast growth factor 21 (Fgf21) in the liver. Mango fruit powder treatment significantly counteracted the high-fat induced overexpression of Fgf21 at all doses tested and at the highest dose for Insr (Fig. 3).

Relative mRNA expressions of peroxisome proliferator-activated receptor gamma coactivator 1 alpha (Ppargc1a), adipose triglyceride lipase (Pnpla2), perilipin 2, leptin receptor b (Leprb), adiponectin receptor 1 (Adipor1), insulin receptor substrate 1 (Irs1), glucose transporter 2 (Slc2a2), and 6-phosphofructo-2-kinase/fructose-2,6-biphosphatase 3 (Pfkfb3) in the liver were neither altered by the high-fat diet (HFC compared to NFC) nor mango fruit powder treatment (T1-T3 compared to HFC; data not shown).

Effects of mango fruit powder on the expression of genes related to fatty acid and glucose oxidation and insulin signaling in skeletal muscle

As shown in Fig. 4A, intake of the HFC diet significantly increased relative mRNA levels of Ppara, Cpt1b, and Pnpla2, but not of Sirt1, in skeletal muscle compared to control mice. Mango fruit powder treatment did not affect Ppara and Pnpla2 expression, but increased relative Cpt1b mRNA levels in a dose-dependent manner. Moreover, mango fruit powder treatment at the highest dose significantly increased relative Sirt1 mRNA levels compared to HFC. Relative Ppargc1a mRNA expression was similar in all groups (data not shown). Moreover, HFC diet intake significantly decreased Prkaa2 (the predominat catalytic subunit [31]) and increased Prkaa1 mRNA expression in skeletal muscle compared to the NFC group. A tendency to counteract the high-fat diet-induced decrease in Prkaa2 mRNA expression was observed in animals receiving the mango fruit powder treatment, but it did not affect the expression of Prkaa1 in skeletal muscle compared to the HFC group. Similarly, intake of the HFC diet significantly decreased AMPK $\alpha$ protein levels in skeletal muscle compared to the NFC group, and mice receiving mango fruit powder treatment showed a tendency to counteract this high-fat diet-induced decrease (Fig. 4B), but it did not affect the phosphorylation status on Thr172 of the kinase among groups (Fig. 4C). 


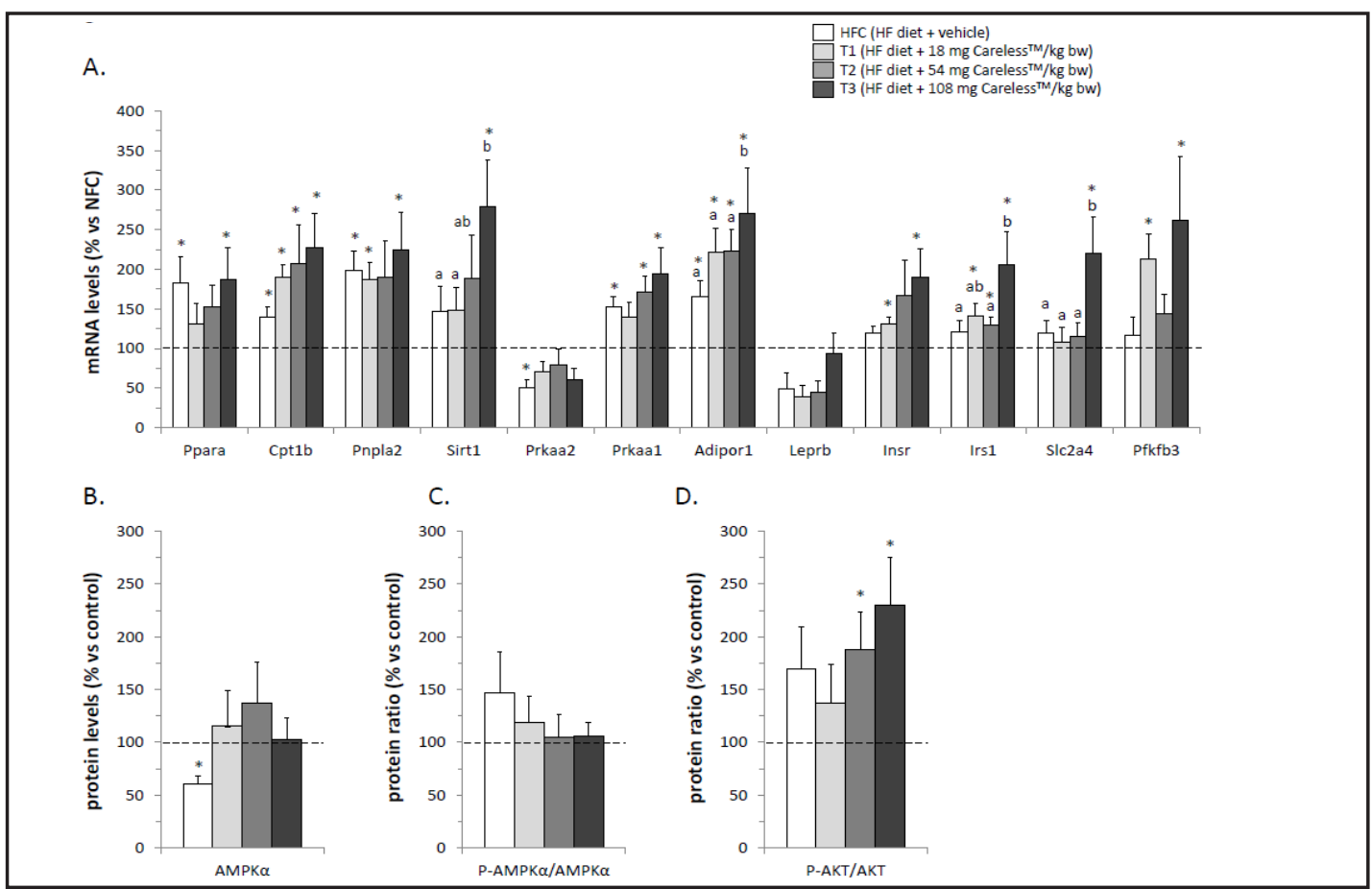

Fig. 4. Effect of mango fruit powder suplementation on transcriptional response (A), AMP-activated protein kinase $\alpha$ (AMPK $\alpha$ ) levels and phosphorylation status on Thr172 (B and C), and protein kinase B (AKT) phosphorylation status on Ser473 (D) in gastrocnemius muscle of high-fat diet-fed animals. Obesity-prone mice were fed for 10 weeks with a high-fat diet (HFC group) or a high-fat diet with simultaneous oral daily treatment with 18, 54, or $108 \mathrm{mg} / \mathrm{kg}$ bw/day of mango fruit powder (T1, T2, and T3 group, respectively), whereas control animals were fed a normal fat standard chow diet (NFC group). The specific mRNA levels were quantified by real-time RT-PCR and normalized to the expression of the reference gene Rplp0. The specific protein levels were quantified by Western blot and, to quantify the total amount, were normalized to the expression of HSP90 protein. Data are the means \pm SEM ( $n=9-12$, except for Lepr mRNA levels $n=7-10$ due to its very low expression levels) and are expressed relative to the mean value of the NFC group, which was set to 100. The horizontal dotted line represents the mean of the NFC group. Statistically significant differences between treatments in high-fat diet-fed animals were tested by one-way ANOVA and least-significant difference $(\mathrm{LSD})$ post hoc comparisons $(\mathrm{P}<0.05)$ and values not sharing a common letter were statistically different. Statistically significant differences versus NFC group were assessed by a two-tailed Student's $t$ test $(\mathrm{P}<0.05)$ and indicated by an asterisk.

Relative mRNA expression of Adipor1 was significantly increased and Leprb decreased in HFC compared to NFC group (Fig. 4A). Mango fruit powder treatment, at the highest dose (T3), increased relative mRNA levels of Adipor1, Irs1, and Slc2a4; furthermore, relative mRNA levels of Leprb, Insr, and Pfkfb3 also showed a tendency to increase compared to HFC (Fig. 4A). In addition, protein kinase B (AKT) levels exhibited a tendency to decrease with HFC diet intake (data not shown) without affecting its phosphorylation status on Ser473 (Fig. 4D) in skeletal muscle compared to NFC group. Mango fruit powder treatment did not counteract the high-fat diet effect on AKT protein levels (data not shown); nevertheless, at the higher doses of mango fruit powder tested (T2 and T3), a significant increase in AKT phosphorylation on Ser473 in skeletal muscle was observed compared to the NFC group (Fig. 4D).

\section{Discussion}

In mice fed the HFC diet, body weight, body fat, weight of adipose tissues, and triglyceride content in the liver were significantly increased, and insulin sensitivity significantly 
decreased compared to animals fed the NFC diet (as seen in other studies [32, 33]). Developing anti-obesity agents, in particular natural extracts rich in polyphenols, with hepatoprotective properties and/or insulin sensitive actions, has become of significant interest to both biomedical researchers and clinicians $[32,33]$. Our findings suggest that treatment with the mango fruit powder tested exerts physiological protective effects in the initial stages of hepatic lipid accumulation and insulin resistance induced by a high-fat diet in mice. The most effective dose was estimated to be around $54 \mathrm{mg} / \mathrm{kg}$ bw/day. At this dose, animals seemed to be protected, at least in part, from the main adverse effects derived from the consumption of a high-fat diet, namely hepatic fat accumulation and development of insulin resistance. Interestingly, both beneficial effects were observed even though they were not necessarily accompanied by a reduced body and fat weight gain of the animals, as seen in the highest dose used in this study.

As expected [34, 35], in response to the intake of a moderate high-fat diet (45\% energy as fat), we observed an increased expression of genes involved in fatty acid oxidation and mobilization in liver (Fig. 3), skeletal muscle (Fig. 4A), and brown adipose tissue (BAT; data not shown) to compensate the excess lipid available. Mango fruit powder treatment enhanced fatty acid oxidation capacity in the liver and skeletal muscle, as suggested by the treatment-related increases in the expression of genes associated to fatty acid oxidation (i.e. Ppara and Cpt1); however, this was not seen in BAT (data not shown). These results might contribute to explain the observed effect regarding liver TG content (Fig. 1), which was significantly higher in HFC animals compared to NFC animals as a result of excess lipid intake, whereas animals treated with mango fruit powder were protected against this increase, particularly those with higher doses. Benefits on hepatic lipid profiles of mango fruit powder (5 and $10 \mathrm{~g}$ ) in fluoride-induced metabolic toxicity have also been reported in rats [36]. The effect may be due to the active molecule MGF, which is present in our mango fruit powder [18]. It has been reported that MGF may ameliorate high-fat diet-induced hepatic TG accumulation and may decrease FFA and TG while increasing plasma beta-hydroxybutyrate levels in rodents [37-39], partly by modulating the expression of genes involved in lipid oxidation and mitochondrial bioenergetics in key metabolic tissues [37-40]. In a randomized, doubleblind, controlled trial in humans, MGF supplementation (150 mg/day, 12 weeks) improved serum lipid profiles in overweight patients with hyperlipidemia [17]. Moreover, it has been also reported that mangiferin significantly increases FFA uptake and significantly decreases TG accumulation by activation of AMPK and its downstream proteins, fatty acid translocase CD36 and Cpt1a, both involved in lipid catabolism, in HepG2 cells [39]. These results suggest that MGF, a component of the mango fruit powder used in this study, promotes FFA uptake and oxidation and inhibits TG accumulation by regulating the expression of key enzymes, at least in liver, through the AMPK pathway. Interestingly, it has been shown that the mango fruit powder Careless ${ }^{\mathrm{TM}}$ is able to activate AMPK in HepaRG cells [19] and enables mitochondrial biogenesis in C2C12 muscle cells and HepG2 cells [19] as seen for MGF, even at a dose that has a 250 times lower content of MGF [19]. These results indicate that mangiferin is not the only active ingredient in mango fruit powder Careless ${ }^{\mathrm{TM}}$ exerting these effects.

In our study, increased liver TG content was associated with increased insulin resistance in HFC compared to NFC animals. At present, it is unclear whether insulin resistance causes hepatic TG accumulation or whether an increased hepatic TG content per se reduces insulin sensitivity (reviewed in [41]).

Furthermore, we observed that at the beginning of the dietary challenge and intervention, the intake of a high-fat diet caused an increase of fasting glucose concentration $[42,43]$ (week 1; Fig. 2), which progressively decreased to baseline levels; simultaneously, fasting insulin levels increased as a compensatory mechanism (weeks 5 and 9). In animals fed the HFC diet and those fed the lowest mango fruit powder dose, the HOMA-IR score significantly increased over time, indicating reduced insulin sensitivity as a result of the high-fat diet [44]. Higher doses of mango fruit powder (T2 and T3), however, improved the high-fat diet-induced insulin sensitivity, as indicated by lower fasting insulin and a lower HOMA-IR score (Fig. 2). Glucose intolerance present in the early stages of high-fat diet- 
induced obesity has been described to be associated with an enlarged adipose tissue depot, adipose tissue inflammation, and excess hepatic lipids rather than impairments in muscle insulin sensitivity [35].

As a consequence of the high-fat diet-induced development of insulin resistance (or to compensate the positive energy balance), we observed tissue-specific gene-expression adaptations compared to NFC feeding. In liver we observed an increase in Insr and hepatokine Fgf21 mRNA expression levels (Fig. 3), whereas in WAT, a decrease in mRNA expression levels of Insr compared to control animals was seen (data not shown), as previously reported [45, 46], indicating a dysfunctional adipose tissue, resulting in an increased flux of FFAs to the liver or muscle cells and other organs. In skeletal muscle, we observed some adaptations (i.e. an increased expression of Adipor1 and a tendency to lower Leprb mRNA levels; Fig. 4A) which were probably associated to higher circulating leptin/adiponectin concentrations ratio. This in turn could be the direct result of high-fat diet-induced WAT expansion and also, perhaps, an indirect consequence of insulin function impairment in WAT of high-fat diet-fed animals, since these adipokines enhance $\beta$-oxidation of FFAs in the mitochondria of peripheral tissues $[47,48]$. Interestingly, mango fruit powder treatment improved insulin sensitivity in high-fat diet-fed mice along with a reduction of fasting insulinemia by counteracting high-fat diet-induced changes in the expression of Insr and the hepatokine Fgf21 in the liver (Fig. 3), by increasing the expression of genes related to insulin action and glucose utilization in skeletal muscle (Fig. 4A) and, to a lesser extent, in white adipose tissue (WAT; data not shown). The protection offered by the higher doses of mango fruit powder (T2 and T3) from high-fat diet-induced insulin resistance was confirmed by the increase in the phosphorylation on Ser473 of the insulin receptor downstream kinase AKT in skeletal muscle (Fig. 4D). In WAT, the improvement of insulin sensitivity was accompanied by an increased fat deposition and (secondary) serum leptin levels in the high-fat diet-fed animals treated with the highest dose of the mango fruit powder (Table 2 and Table 3). This may probably reflect a healthy insulin-sensitive adipose tissue [49], which would be able to expand physiologically in response to a positive energy balance. In fact, clinical use of most anti-diabetics, even insulin, is accompanied by excessive weight gain and increased fat deposition [50]. These metabolic changes are in agreement with a significant reduction in plasma glucose levels and hepatic carbohydrate parameters, together with benefits on hepatic lipid profiles, elicited by supplementation with mango fruit powder (5 and $10 \mathrm{~g}$ ) in fluoride-induced metabolic toxicity previously reported in rats [36]. In addition, a pilot study in humans showed that a 12-week supplementation with freeze-dried mango significantly reduced blood glucose levels in both male and female participants [16].

It has been reported that MGF may protect against hyperglycemia, hyperinsulinemia, and insulin resistance in high-fat diet-fed mice [51], in diabetic insulin-resistant rats [37], and in overweight patients [17], as well as against accelerated glucose uptake and utilization in cultured adipocytes and myotubes [51,52]. However, MGF did not significantly affect fatty acid oxidation even under a high-fat dietary challenge [51]. Other major phenolic compounds found in mango fruit powder Careless ${ }^{\mathrm{TM}}$, such as gallic acid or rutin [18], have been reported to up-regulate genes involved in lipolysis and fatty acid oxidation in adipocytes [53]. Therefore, it is suggested that it is the combination rather than the individual constituents of mango fruit powder tested that are responsible for its main effects in skeletal muscle of high-fat diet-fed mice.

AMPK activity is reduced in hyperinsulinemic obese rodents and humans compared to their healthy counterparts, which is considered an early event in the development of insulin resistance in response to nutrient excess (reviewed in [54]). We reported a decrease in the mRNA levels of the predominant catalytic subunit alpha of AMPK in liver and in skeletal muscle (Prkaa1 and Prkaa2 respectively [31]; Fig. 3 and 4A) and a decrease in the total protein levels of AMPK $\alpha$ (Fig. 4B). However, in the skeletal muscle this was not observed regarding their phosphorylation status on Thr172 (Fig. 4C) in response to the HFC compared to the NFC diet, indicating that a high fat intake can impair expression and thus the global tissue activity of AMPK $\alpha$. Our results show that mango fruit powder treatment counteracts 


\section{Cellular Physiology Cell Physiol Biochem 2017;42:564-578 \begin{tabular}{l|l} 
DOI: 10.1159/000477606 & O 2017 The Author(s). Published by S. Karger AG, Basel \\
www.karger.com/cpb
\end{tabular} \\ Sabater et al.: Mango Fruit on Early Metabolic Adverse Effects of a High-Fat Diet}

the high-fat diet-induced decrease in the mRNA levels of the predominant catalytic subunit alpha of AMPK in liver and in skeletal muscle (Prkaa1 and Prkaa2, respectively; Fig. 3 and $4 \mathrm{~A})$ and in the total protein levels of $\mathrm{AMPK} \alpha$, without affecting their phosphorilation on Thr172 in the skeletal muscle (Fig. 4B and 4C). A similar AMPK response has been described associated to the beneficial effects of crude triterpenoid saponins from I. latifolia in a mouse model of HFD-induced NAFLD [55]. This is in agreement with previous findings showing

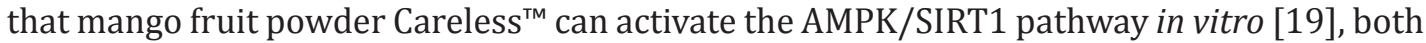
of which are involved in energy homeostasis and glucose and lipid metabolism (reviewed in $[56,57])$. It is widely accepted that AMPK activation enhances insulin sensitivity in a variety of tissues, including liver, adipose tissue, and skeletal muscle [58, 59]. As previously reported $[19,39]$, some of these effects can be attributed to MGF. We also observed a clear dose-dependent increase in Sirt1 expression in skeletal muscle (Fig. 4) in response to mango fruit powder treatment. Nevertheless, Sirt1 expression in liver, which is already induced by feeding a high-fat diet to ameliorate hepatic lipid accumulation [60], did not show an additional enhancement in response to mango fruit powder treatment. Thereby, both AMPK and SIRT1 appear as key regulators of the improvement of fatty acid oxidation capacity and (together with better insulin sensitivity) of the increased glucose uptake and metabolism through the glycolytic pathway in liver and skeletal muscle of mango fruit powder-treated mice fed a high-fat diet.

It is known that enhancing fatty acid oxidation reduces fat accumulation; however, it may not directly alleviate hyperglycemia, because fatty acid oxidation inhibits glucose utilization [61]. Dietary overconsumption of fats enhances fatty acid utilization but induces metabolic inflexibility and insulin resistance [62], even when accompanied by increased oxidative capacities and mitochondrial density $[63,64]$. Our results suggest that mango fruit powder treatment enhanced both fat oxidation and glucose utilization, which could improve glucose profiles and mitigate insulin resistance, thus overcoming the conundrum that weakens strategies based only on increasing fatty acid oxidation. In addition, mango fruit powder treatment significantly increased the gene expression of uncoupling protein 1 in visceral WAT and BAT (data not shown) compared to NFC group, suggesting an enhanced thermogenic function in these tissues, which is beyond the scope of this paper and deserves further investigation.

In summary, the results obtained in this study suggest that mango fruit powder Careless $^{\mathrm{TM}}$ intake exerts physiological protective effects in the initial steps of insulin resistance and hepatic lipid accumulation induced by a high-fat diet in mice. The effects appear to be mediated through the AMPK/SIRT1 pathway by improving insulin sensitivity, increasing glucose uptake and metabolism through the glycolytic pathway capacity in liver and skeletal muscle, and modulating the hepatic lipid profile.

\section{Acknowledgments}

This study was sponsored by Vital Solutions Swiss AG. The authors thank Enzo Ceresi for his help in the histological studies.

\section{Disclosure Statement}

A.G.S., T.P., J.R. and A.P. have no conflict of interest, financial or scientific. I.V., S.F., and S.B.W. are employed by Vital Solutions. Vital Solutions Swiss AG owns the proprietary ingredient used in the study. During study realization and data analysis, all data were completely blinded, and study realization, data analysis and report generating was undertaken independently from the sponsors.

\section{KARGER}




\section{Cellular Physiology Cell Physiol Biochem 2017;42:564-578 \begin{tabular}{l|l} 
and Biochemistry Published onlIne: June 05, 2017 & $\begin{array}{l}\text { (c) } 2017 \text { The Author(s). Published by S. Karger AG, Basel } \\
\text { www.karger.com/cpb }\end{array}$
\end{tabular}}

\section{References}

1 Steinbeck KS: Insulin resistance syndrome in children and adolescents: clinical meaning and indication for action. Int J Obes Relat Metab Disord 2004;28:829-832.

2 Ohnishi H, Saitoh S, Ura N, Takagi S, Obara F, Akasaka H, Oimatsu H, Shimamoto K: Relationship between insulin resistance and accumulation of coronary risk factors. Diabetes Obes Metab 2002;4:388-393.

3 Ioannou GN, Bryson CL, Boyko EJ: Prevalence and trends of insulin resistance, impaired fasting glucose, and diabetes. J Diabetes Complications 2007;21:363-370.

4 Storlien LH, Jenkins AB, Chisholm DJ, Pascoe WS, Khouri S, Kraegen EW: Influence of dietary fat composition on development of insulin resistance in rats. Relationship to muscle triglyceride and omega-3 fatty acids in muscle phospholipid. Diabetes 1991;40:280-289.

-5 Samuel VT, Shulman GI: The pathogenesis of insulin resistance: integrating signaling pathways and substrate flux. J Clin Invest 2016;126:12-22.

-6 Bellentani S, Scaglioni F, Marino M, Bedogni G: Epidemiology of non-alcoholic fatty liver disease. Dig Dis 2010;28:155-161.

7 Bellentani S, Marino M: Epidemiology and natural history of non-alcoholic fatty liver disease (NAFLD). Ann Hepatol 2009;8 Suppl 1:S4-8.

8 Mishra A, Younossi ZM: Epidemiology and Natural History of Non-alcoholic Fatty Liver Disease. J Clin Exp Hepatol 2012;2:135-144.

9 Younossi ZM, Koenig AB, Abdelatif D, Fazel Y, Henry L, Wymer M: Global Epidemiology of Non-Alcoholic Fatty Liver Disease-Meta-Analytic Assessment of Prevalence, Incidence and Outcomes. Hepatology 2015;

10 Garrido-Suarez BB, Garrido G, Delgado R, Bosch F, del CRM: A Mangifera indica L. extract could be used to treat neuropathic pain and implication of mangiferin. Molecules 2010;15:9035-9045.

11 Jahurul MH, Zaidul IS, Ghafoor K, Al-Juhaimi FY, Nyam KL, Norulaini NA, Sahena F, Mohd Omar AK: Mango (Mangifera indica L.) by-products and their valuable components: a review. Food Chem 2015;183:173-180.

12 Shah KA, Patel MB, Patel RJ, Parmar PK: Mangifera Indica (Mango). Pharmacogn Rev 2010;4:42-48.

13 Fahmy SR, Amien AI, Abd-Elgleel FM, Elaskalany SM: Antihepatotoxic efficacy of Mangifera indica L. polysaccharides against cyclophosphamide in rats. Chem Biol Interact 2016;244:113-120.

14 Gondi M, Basha SA, Bhaskar JJ, Salimath PV, Rao UJ: Anti-diabetic effect of dietary mango (Mangifera indica L.) peel in streptozotocin-induced diabetic rats. J Sci Food Agric 2015;95:991-999.

15 Oluwole OG, Esume C: Anti-inflammatory effects of aqueous extract of Mangifera indica in Wistar rats. J Basic Clin Physiol Pharmacol 2015;26:313-315.

-16 Evans SF, Meister M, Mahmood M, Eldoumi H, Peterson S, Perkins-Veazie P, Clarke SL, Payton M, Smith BJ, Lucas EA: Mango supplementation improves blood glucose in obese individuals. Nutr Metab Insights 2014;7:77-84.

17 Na L, Zhang Q Jiang S, Du S, Zhang W, Li Y, Sun C, Niu Y: Mangiferin supplementation improves serum lipid profiles in overweight patients with hyperlipidemia: a double-blind randomized controlled trial. Sci Rep 2015;5:10344.

18 Gerstgrasser A, Röchter S, Dressler D, Schon C, Reule C, Buchwald-Werner S: In Vitro Activation of eNOS by Mangifera indica (Careless) and Determination of an Effective Dosage in a Randomized, Double-Blind, Human Pilot Study on Microcirculation. Planta Med 2016;82:298-304.

19 Röchter S, Ehrhardt C, Buchwald-Werner S, Berger-Büter K, Schatton E: Benefits of a Mangifera indica L. fruit powder for well-aging - In vitro investigation of effects on master regulators for the aging process. Agro Food Ind Hi Tech 2015;26: 4-7.

20 Mura M, Palmieri D, Garella D, Di Stilo A, Perego P, Cravotto G, Palombo D: Simultaneous ultrasoundassisted water extraction and beta-cyclodextrin encapsulation of polyphenols from Mangifera indica stem bark in counteracting TNFalpha-induced endothelial dysfunction. Nat Prod Res 2015;29:1657-1663.

21 Muris DM, Houben AJ, Schram MT, Stehouwer CD: Microvascular dysfunction: an emerging pathway in the pathogenesis of obesity-related insulin resistance. Rev Endocr Metab Disord 2013;14:29-38.

-22 Reynés B, Palou M, Palou A: Gene expression modulation of lipid and central energetic metabolism related genes by high-fat diet intake in the main homeostatic tissues. Food Funct 2017;8:629-650.

23 Reagan-Shaw S, Nihal M, Ahmad N: Dose translation from animal to human studies revisited. FASEB J 2008;22:659-661. 


\section{Cellular Physiology Cell Physiol Biochem 2017;42:564-578 \begin{tabular}{l|l} 
DOI: 10.1159/000477606 & O 2017 The Author(s). Published by S. Karger AG, Basel \\
www.karger.com/cpb
\end{tabular}

24 Matthews DR, Hosker JP, Rudenski AS, Naylor BA, Treacher DF, Turner RC: Homeostasis model assessment: insulin resistance and beta-cell function from fasting plasma glucose and insulin concentrations in man. Diabetologia 1985;28:412-419.

25 Petrov PD, Ribot J, Palou A, Bonet ML: Improved metabolic regulation is associated with retinoblastoma protein gene haploinsufficiency in mice. Am J Physiol Endocrinol Metab 2015;308:E172-183.

-26 Bustin SA, Benes V, Garson JA, Hellemans J, Huggett J, Kubista M, Mueller R, Nolan T, Pfaffl MW, Shipley GL, Vandesompele J, Wittwer CT: The MIQE guidelines: minimum information for publication of quantitative real-time PCR experiments. Clin Chem 2009;55:611-622.

-27 Ruijter JM, Ramakers C, Hoogaars WM, Karlen Y, Bakker O, van den Hoff MJ, Moorman AF: Amplification efficiency: linking baseline and bias in the analysis of quantitative PCR data. Nucleic Acids Res 2009;37:e45.

28 Livak KJ, Schmittgen TD: Analysis of relative gene expression data using real-time quantitative PCR and the 2(-Delta Delta C(T)) Method. Methods 2001;25:402-408.

29 Nalbantoglu IL, Brunt EM: Role of liver biopsy in nonalcoholic fatty liver disease. World J Gastroenterol 2014;20:9026-9037.

-30 Carter-Kent C, Brunt EM, Yerian LM, Alkhouri N, Angulo P, Kohli R, Ling SC, Xanthakos SA, Whitington PF, Charatcharoenwitthaya P, Yap J, Lopez R, McCullough AJ, Feldstein AE: Relations of steatosis type, grade, and zonality to histological features in pediatric nonalcoholic fatty liver disease. J Pediatr Gastroenterol Nutr 2011;52:190-197.

-31 Jørgensen SB, Viollet B, Andreelli F, Frøsig C, Birk JB, Schjerling P, Vaulont S, Richter EA, Wojtaszewski JF: Knockout of the alpha2 but not alpha1 5'-AMP-activated protein kinase isoform abolishes 5-aminoimidazole-4-carboxamide-1-beta-4-ribofuranosidebut not contraction-induced glucose uptake in skeletal muscle. J Biol Chem 2004;279:1070-1079.

-32 Xi Y, Wu M, Li H, Dong S, Luo E, Gu M, Shen X, Jiang Y, Liu Y, Liu H: Baicalin Attenuates High Fat Diet-Induced Obesity and Liver Dysfunction: Dose-Response and Potential Role of CaMKK $\beta /$ AMPK/ACC Pathway. Cell Physiol Biochem 2015;35:2349-2359.

-33 Qiang G, Yang X, Shi L, Zhang H, Chen B, Zhao Y, Zu M, Zhou D, Guo J, Yang H, Zhang L, Du G: Antidiabetic Effect of Salvianolic Acid A on Diabetic Animal Models via AMPK Activation and Mitochondrial Regulation. Cell Physiol Biochem 2015;36:395-408.

34 Priego T, Sanchez J, Pico C, Palou A: Sex-differential expression of metabolism-related genes in response to a high-fat diet. Obesity (Silver Spring) 2008;16:819-826.

35 Trajcevski KE, O'Neill HM, Wang DC, Thomas MM, Al-Sajee D, Steinberg GR, Ceddia RB, Hawke TJ: Enhanced lipid oxidation and maintenance of muscle insulin sensitivity despite glucose intolerance in a diet-induced obesity mouse model. PLoS One 2013;8:e71747.

-36 Karn SS, Narasimhacharya AV: Physiologic and Metabolic Benefits of Formulated Diets and Mangifera indica in Fluoride Toxicity. J Diet Suppl 2015;12:153-172.

37 Saleh S, El-Maraghy N, Reda E, Barakat W: Modulation of diabetes and dyslipidemia in diabetic insulinresistant rats by mangiferin: role of adiponectin and TNF-alpha. An Acad Bras Cienc 2014;86:1935-1948.

-38 Guo F, Huang C, Liao X, Wang Y, He Y, Feng R, Li Y, Sun C: Beneficial effects of mangiferin on hyperlipidemia in high-fat-fed hamsters. Mol Nutr Food Res 2011;55:1809-1818.

39 Niu Y, Li S, Na L, Feng R, Liu L, Li Y, Sun C: Mangiferin decreases plasma free fatty acids through promoting its catabolism in liver by activation of AMPK. PLoS One 2012;7:e30782.

40 Lim J, Liu Z, Apontes P, Feng D, Pessin JE, Sauve AA, Angeletti RH, Chi Y: Dual mode action of mangiferin in mouse liver under high fat diet. PLoS One 2014;9:e90137.

41 Lockman KA, Nyirenda MJ: Interrelationships between hepatic fat and insulin resistance in non-alcoholic fatty liver disease. Curr Diabetes Rev 2010;6:341-347.

42 Ribot J, Rodríguez AM, Rodríguez E, Palou A: Adiponectin and resistin response in the onset of obesity in male and female rats. Obesity (Silver Spring) 2008;16:723-730.

43 Voigt A, Ribot J, Sabater AG, Palou A, Bonet ML, Klaus S: Identification of Mest/Peg1 gene expression as a predictive biomarker of adipose tissue expansion sensitive to dietary anti-obesity interventions. Genes Nutr 2015;10:477.

44 Palou M, Torrens JM, Priego T, Sánchez J, Palou A, Picó C: Moderate caloric restriction in lactating rats programs their offspring for a better response to HF diet feeding in a sex-dependent manner. J Nutr Biochem 2011;22:574-584. 


\section{Cellular Physiology Cell Physiol Biochem 2017;42:564-578 \begin{tabular}{l|l} 
DOI: 10.1159/000477606 & Ond Biochemistry 2017 The Author(s). Published by S. Karger AG, Basel \\
wwww.karger.com/cpb
\end{tabular}

45 Murata Y, Nishio K, Mochiyama T, Konishi M, Shimada M, Ohta H, Itoh N: Fgf21 impairs adipocyte insulin sensitivity in mice fed a low-carbohydrate, high-fat ketogenic diet. PLoS One 2013;8:e69330.

-46 McAllan L, Keane D, Schellekens H, Roche HM, Korpela R, Cryan JF, Nilaweera KN: Whey protein isolate counteracts the effects of a high-fat diet on energy intake and hypothalamic and adipose tissue expression of energy balance-related genes. Br J Nutr 2013;110:2114-2126.

47 Tsatsoulis A, Mantzaris MD, Bellou S, Andrikoula M: Insulin resistance: an adaptive mechanism becomes maladaptive in the current environment - an evolutionary perspective. Metabolism 2013;62:622-633.

48 Havel PJ: Update on adipocyte hormones: regulation of energy balance and carbohydrate/lipid metabolism. Diabetes 2004;53 Suppl 1:S143-151.

49 Church C, Horowitz M, Rodeheffer M: WAT is a functional adipocyte? Adipocyte 2012;1:38-45.

50 Li C, Kong D: Cancer risks from diabetes therapies: evaluating the evidence. Pharmacol Ther 2014;144:7181.

-51 Apontes P, Liu Z, Su K, Benard O, Youn DY, Li X, Li W, Mirza RH, Bastie CC, Jelicks LA, Pessin JE, Muzumdar RH, Sauve AA, Chi Y: Mangiferin stimulates carbohydrate oxidation and protects against metabolic disorders induced by high-fat diets. Diabetes 2014;63:3626-3636.

52 Kumar BD, Krishnakumar K, Jaganathan SK, Mandal M: Effect of Mangiferin and Mahanimbine on Glucose Utilization in 3T3-L1 cells. Pharmacogn Mag 2013;9:72-75.

53 Liu HW, Tsai YT, Chang SJ: Toona sinensis leaf extract inhibits lipid accumulation through up-regulation of genes involved in lipolysis and fatty acid oxidation in adipocytes. J Agric Food Chem 2014;62:5887-5896.

54 Coughlan KA, Valentine RJ, Ruderman NB, Saha AK: Nutrient Excess in AMPK Downregulation and Insulin Resistance. J Endocrinol Diabetes Obes 2013;1:1008.

55 Feng RB, Fan CL, Liu Q Liu Z, Zhang W, Li YL, Tang W, Wang Y, Li MM, Ye WC: Crude triterpenoid saponins from Ilex latifolia (Da Ye Dong Qing) ameliorate lipid accumulation by inhibiting SREBP expression via activation of AMPK in a non-alcoholic fatty liver disease model. Chin Med 2015;10:23.

-56 Zhang BB, Zhou G, Li C: AMPK: an emerging drug target for diabetes and the metabolic syndrome. Cell Metab 2009;9:407-416.

57 Nogueiras R, Habegger KM, Chaudhary N, Finan B, Banks AS, Dietrich MO, Horvath TL, Sinclair DA, Pfluger PT, Tschöp MH: Sirtuin 1 and sirtuin 3: physiological modulators of metabolism. Physiol Rev 2012;92:14791514.

58 Hegarty BD, Turner N, Cooney GJ, Kraegen EW: Insulin resistance and fuel homeostasis: the role of AMPactivated protein kinase. Acta Physiol (Oxf) 2009;196:129-145.

59 Pehmøller C, Treebak JT, Birk JB, Chen S, Mackintosh C, Hardie DG, Richter EA, Wojtaszewski JF: Genetic disruption of AMPK signaling abolishes both contraction- and insulin-stimulated TBC1D1 phosphorylation and 14-3-3 binding in mouse skeletal muscle. Am J Physiol Endocrinol Metab 2009;297:E665-675.

60 Xu F, Li Z, Zheng X, Liu H, Liang H, Xu H, Chen Z, Zeng K, Weng J: SIRT1 mediates the effect of GLP-1 receptor agonist exenatide on ameliorating hepatic steatosis. Diabetes 2014;63:3637-3646.

61 Nuutila P, Koivisto VA, Knuuti J, Ruotsalainen U, Teräs M, Haaparanta M, Bergman J, Solin O, Voipio-Pulkki LM, Wegelius U: Glucose-free fatty acid cycle operates in human heart and skeletal muscle in vivo. J Clin Invest 1992;89:1767-1774.

62 Hue L, Taegtmeyer H: The Randle cycle revisited: a new head for an old hat. Am J Physiol Endocrinol Metab 2009;297:E578-591.

63 Hancock CR, Han DH, Chen M, Terada S, Yasuda T, Wright DC, Holloszy JO: High-fat diets cause insulin resistance despite an increase in muscle mitochondria. Proc Natl Acad Sci U S A 2008;105:7815-7820.

64 Turner N, Bruce CR, Beale SM, Hoehn KL, So T, Rolph MS, Cooney GJ: Excess lipid availability increases mitochondrial fatty acid oxidative capacity in muscle: evidence against a role for reduced fatty acid oxidation in lipid-induced insulin resistance in rodents. Diabetes 2007;56:2085-2092. 